Technical Report 5-33267

Contract No. NAS8-38609

Delivery Order No. 80

\title{
Probability of Detection of Defects in Coatings with Electronic Shearography
} (5-33267)

Final Technical Report for Period 3 June 1993 through 2 June 1994

July 1994

Prepared by

Gary A. Maddux

Charles M. Horton

Matthew D. Lansing

William J. Gnacek

Patrick L. Newton

Research Institute

The University of Alabama in Huntsville Huntsville, Alabama 35899

Prepared for

George C. Marshall Space Flight Center National Aeronautics and Space Administration Marshall Space Flight Center, AL 35812 Attn: EH13 (Dr. Samuel S. Russell) 


\section{PREFACE}

This technical report was prepared by the staff of the Research Institute, The University of Alabama in Huntsville. The purpose of this report is to provide documentation of the work performed and results obtained under delivery order 80 of Marshall Space Flight Center (MSFC) Contract No. NAS8-38609. Mr. Gary A. Maddux and Mr. Charles M. Horton were Principal Investigators for this twelve month level of effort. Dr. Samuel S. Russell of the Nondestructive Evaluation Branch provided technical coordination.

The views, opinions, and/or findings contained in this report are those of the author(s) and should not be construed as an official NASA position, policy, or decision unless so designated by other official documentation.

I have reviewed this report, dated if $A_{u G} 94$ and the report contains no classified information.

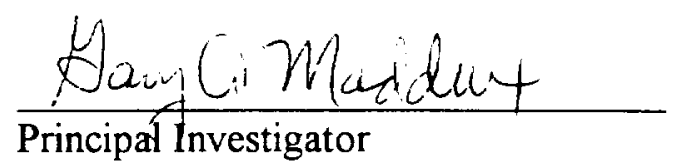




\section{TABLE OF CONTENTS}

$1.0 \quad$ INTRODUCTION

$2.0 \quad$ BACKGROUND AND OBJECTIVES

1

3.0 ACTIVITIES 2

$3.1 \quad$ SPECIMEN DESIGN AND FABRICATION 2

3.1.1 SUBSTRATE AND COATING SPECIFICATIONS 2

3.1.2 DEBOND SIMULATION 2

3.1.2.1 FLUID COUPLING 2

3.1.2.2 SOLID INSERTS 4

3.2 DATA ACQUISITION 4

3.2.1 APPARATUS 4

3.2.2 PROCEDURE 6

$\begin{array}{lll}3.3 & \text { ANALYSIS } & 7\end{array}$

$\begin{array}{lll}3.4 & \text { RESULTS } & 7\end{array}$

$\begin{array}{lll}4.0 & \text { DISCUSSION } & 8\end{array}$

$5.0 \quad$ CONCLUSIONS

$\begin{array}{ll}\text { APPENDICES } & 10\end{array}$

A1.0 PW EH/SIS SHEAROGRAMS 11

A1.1 PANEL 25 11

$\begin{array}{lll}\text { A1.2 PANEL } 26 & 12\end{array}$

A2.0 PW EH/SIS DEBOND SIZE MEASUREMENTS 13

$\begin{array}{lll}\text { A2.1 PANEL 25 } & 13\end{array}$

$\begin{array}{lll}\text { A2.2 PANEL } 26 & 14\end{array}$

A3.0 REFERENCES 16 


\subsection{Introduction:}

The Systems Management and Production Laboratory at the Research Institute, the University of Alabama in Huntsville (UAH), was tasked by the Nondestructive Evaluation (NDE) Branch (EH13) at Marshall Space Flight Center (MSFC) to conduct research in the method of electronic shearography for nondestructive evaluation. The goal of this research was to utilize statistical methods to evaluate the probability of detection (POD) of defects in coatings using electronic shearography. The coating system utilized in the POD studies was to be the paint system currently utilized on the external casings of the NASA Space Transportation System (STS) Revised Solid Rocket Motor (RSRM) boosters. The population of samples was to be large enough to determine the minimum defect size for $90 \%$ probability of detection at $95 \%$ confidence POD on these coatings. Also, the best methods to excite coatings on aerospace components to induce deformations for measurement by electronic shearography were to be determined.

\subsection{Background and Objectives:}

It has been observed that chips of paint occasionally impact the external structure of the space shuttle during and after launch. It is believed that these paint chips originate as debonds in the paint-primer system used on the solid rocket boosters, external tank, or orbiter. The possibility exists for considerable damage to be inflicted upon the vehicle by these high-velocity impacts.

The NDE Branch at MSFC maintains a laboratory for the application and development of the method of electronic shearography. This facility is equipped with a Pratt-Whitney Electronic Holography/Shearography Inspection System (PW EH/SIS) and a Laser Technology, Inc. (LTI) SC4000. ${ }^{1}$ Electronic shearography techniques provide non-contact real-time location and sizing of defects in many material systems. Electronic shearography has proven particularly effective in the evaluation of debonds in laminar material systems, which suggests that the technique should be well suited to the inspection of paint coating systems.

Preliminary to the application of electronic shearography as a field technique to locate and determine the criticality of defects in the STS coating systems, the need was identified to quantify the limitations of the technique for evaluating the type of defects anticipated in those material systems. Also, the methodology for such field evaluation needed to be developed.

The method of performing the POD study was to design and fabricate painted plates containing programmed debonds of various sizes. These panels were then to be inspected in the MSFC NDE Branch Electronic Shearography Laboratory. The results of these inspections would be used to statistically determine the minimum debond size for $90 \%$ probability of detection with $95 \%$ confidence.

\footnotetext{
'Section 3.2.1 APPARATUS contains more information on shearography devices.
} 


\subsection{Activities:}

\subsection{Specimen Design and Fabrication:}

\subsubsection{Substrate and Coating Specifications:}

This project evaluated programmed debonds in the metal substrate and epoxy paint used for the STS RSRM external structure. The substrates utilized were 8 in. $\times 12$ in. $\times$ 0.25 in. thick plates of cold rolled D6AC steel. The coating system was composed of Rustoleum 9334 epoxy primer undercoat and 9392 flat white epoxy topcoat. The coating was applied per NASA specification STW7-3859 by J\&A Finishing (Huntsville, AL). This specification requires a thickness of each of the primer and topcoat between 1.5 and 4 mils. The combined coating thickness was verified by an eddy current method

\subsubsection{Debond Simulation:}

\subsubsection{Fluid Coupling:}

Numerous attempts were made to fabricate simulated debonds in the coating systems. All of the initial attempts involved the controlled application of a fluid to the substrate before the paint system was applied. A template was used to screen most of the panel and allow the application of the fluid to regions of prescribed areas. The concept in these debond simulation schemes is that the fluid used prevents the paint from bonding to the steel substrate where the fluid has been applied, thus producing a debond of a programmed size at a predetermined location.

Several fluid types were initially tested, including:

Thompson \& Formby Tri-Flow spray lubricant with Teflon,

WD-40 spray lubricant,

Permatex Naval Jelly rust remover, and

Conoco HD2 grease.

Initial testing of the fluids to be used involved the application by hand of a small quantity and covering the fluid with a coat of spray enamel. The Conoco HD2 grease was demonstrated to provide the most reliable debond simulation. A series of debond patterns of various sizes were cut from sheets of magnetic vinyl sign material to act as a stencil during grease application. However, problems were encountered in the application of this fluid for programmed debonds.

Thiokol Corporation applied the $\mathrm{HD} 2$ with the Sonitech precision spray facility they maintain at MSFC. The machine was adjusted to provide a very fine coat of grease to simulate contamination for another project, and could not be readjusted in the time frame of this project. The thickest coat which could repeatably be applied with this technique was $67 \mathrm{mg} / \mathrm{ft}^{2}$. Assuming a uniform application this quantity of lubricant will result in a layer approximately 0.0299 mils thick.

These specimens did not produce debonds detectable by electronic shearography It is suspected that either the paint was allowed to bond to the steel substrate through the grease or the grease layer was so thin as to create a 'kissing debond'. A kissing debond 
occurs when there is no rigid bonding between laminae, but either the material on both sides of the debond is sufficiently thick/stiff to resist influence by the debond or some force such as friction or coupling viscosity prevents the separation of the laminae. That is, the debond physically exists, but the deformation response of the debond to nondamaging excitation is the same as that of a normal bond. Since electronic shearography measures the motion of the specimens' surfaces, it cannot detect debonds that do not respond to excitation differently than the rest of the bonded region.

In the case of these panels, the ratio of the paint thickness to the underlying grease thickness was 4.5 mils $/ 0.0299$ mils $=150.5$. The fact that the paint was more than 150 times as thick as the grease beneath it indicates that, if the paint over the region of grease is treated as a plate fixed around the edges, there was likely not enough grease to alter the stiffness of the paint above it with respect to the paint around it. Thus, the paint was viscously coupled to the plate surface where the fluid was applied and behaved the same there as where no fluid was present. This behavior is typical of a 'kissing debond'.

Thicker layers of grease were obtained when panels with the same type of stencils were hand sprayed by AC Engineering. However, the deposited grease was found to be highly non-uniform. The specified target thickness for the grease was 2 to 3 mils. A sufficient volume of grease was applied to produce a uniform layer 2.5 mils thick. However, the rectangular interior of the programmed debonds contained less than 1 mil of grease. The remaining fluid ran, puddled around the edges of the pattern, and seeped beneath the stencil. Thus, instead of a somewhat-realistically simulated uniform debond, an unrealistic superposition of a uniform rectangular debond and a rectangular ring-like debond was fabricated. The geometry of these grease regions is depicted in Figure 1.

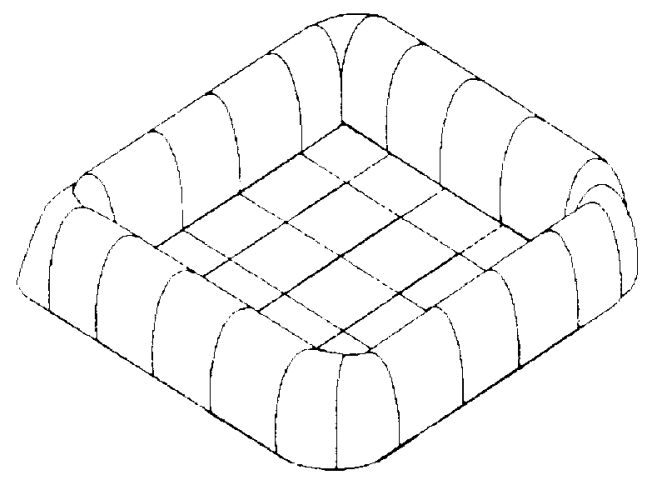

Figure 1.

Hand-Sprayed HD2 Debond Geometry

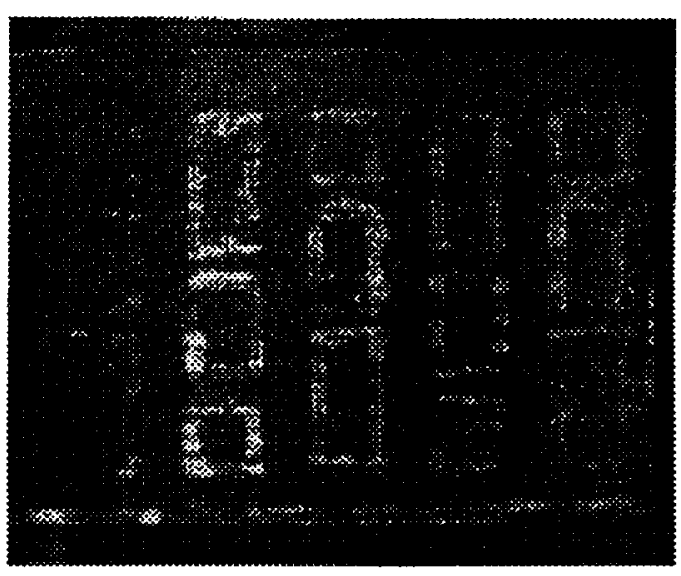

Figure 2.

Hand-Sprayed HD2 Shearogram

A typical shearogram of these panels, taken with the PW EH/SIS is shown in Figure 2. This shearogram was produced with thermal excitation and indicates that the motion of the thick rings around the uniform debonds is much larger than the motion of the uniform regions themselves. It was not possible to produce enough motion in the thin interior regions that their response could be experimentally or analytically separated from the thick outer rings. Thus, the hand sprayed panels did not allow for shearographical detection of the programmed uniform rectangular debonds. 


\subsubsection{Solid Inserts:}

After failing to simulate coating debonds with fluids, solid inserts were used. The concept of simulating coating debonds with solid inserts requires that the insert not be bonded to the substrate. The paint applied to the insert then is not bonded to the substrate.

The first inserts tested were single layer 0.5 mil thick polymer films. However, the unpainted polymer inserts experienced massive plastic deformation with the slightest application of heat. A similar shriveling response was observed upon application of a thin coat of spray enamel before any heat was applied. It could not be concluded that a similar reaction would not occur upon application of the RSRM epoxies, and thus the polymer inserts were deemed unsuitable for this study.

The best preliminary results were obtained with single layer 0.5 mil thick aluminum foil inserts. The use of these inserts required some form of edge bonding that would prevent the foils from leaving or moving around on the surface of the steel plates during shipping and painting while leaving a region of the foil of known size un-bonded to the plate. Initially, hot-melt glue was applied in a very thin bead around all edges of the foil, but this decreased the actual size of the program debonds by an amount that could not be easily determined. Subsequent tests indicated that a small amount of plastic tape $(\cong 1 \times 3$ $\mathrm{mm}$ ) allowed the foils to be anchored around the edges while leaving the entire bottom surface of the foil un-bonded.

Square foils of various sizes, ranging from $3 \mathrm{~mm}$ to $24 \mathrm{~mm}$ on a side in $3 \mathrm{~mm}$ increments, were arranged on the surface of the plates before painting. The foils were placed with plastic tape as shown in Figure 3. The arrangement of foils is shown in Figure 4. Each painted plate contains seven debonds of each of the eight program debond sizes. Two identical panels were prepared, providing a total of 112 physical debonds.

\subsection{Data Acquisition:}

\subsubsection{Apparatus:}

The MSFC NDE Branch Electronic Shearography Laboratory is equipped with two electronic shearography instruments. The Laser Technology, Inc. (LTI) SC-4000 utilizes a birefringent lens to induce a fixed shearing angle. ${ }^{2}$ The shear distance is thus predetermined by the distance the object is from the shearography camera. The shear distance is $0.75 \mathrm{in}$. at an object distance of $8 \mathrm{ft}$. This system produces basic shearograms which are the superposition of a single undeformed and a single deformed image, each of which is the superposition of two sheared images at the same deformation state. For more information on the technique of electronic shearography, a list of references is included in Appendix A3.0.

\footnotetext{
${ }^{2}$ LTI Patent No. 4,887,899.
} 


\begin{tabular}{|c|c|c|c|}
\hline & A,C,E & B,D,F & G \\
\hline 1 & 24 & 3 & 21 \\
\hline 2 & 6 & 21 & 15 \\
\hline 3 & 18 & 9 & 9 \\
\hline 4 & 12 & 15 & 3 \\
\hline 5 & 18 & 9 & 6 \\
\hline 6 & 12 & 15 & 12 \\
\hline 7 & 21 & 6 & 18 \\
\hline 8 & 3 & 24 & 24 \\
\hline
\end{tabular}

Table 1. Programmed Debond Sizes (mm)

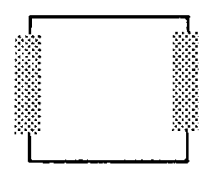

$<18 \mathrm{~mm}$

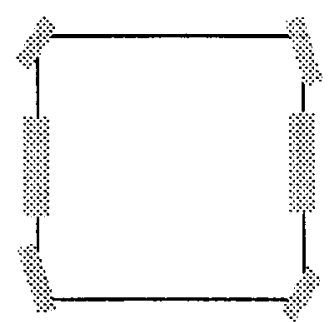

$\geq 18 \mathrm{~mm}$
Figure 3. Foil Placement with Plastic Tape
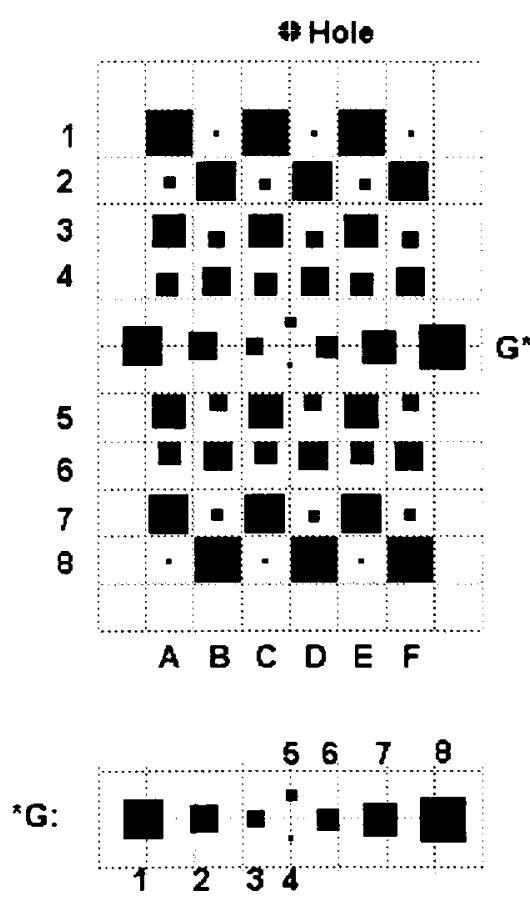

Figure 4.

Foil Insert Programmed Debond Pattern

The Pratt-Whitney Electronic Holography/Shearography Inspection System utilizes a modified Michelson interferometer ${ }^{3}$ and provides several image enhancement functions. Frame averaging acquires a series of images at each deformation state. The number of images acquired is user defined. At each deformation stage the mean intensity of each pixel over the range of frames is used to produce a frame averaged image. This function sharpens the features of the object surface and reduces noise

Speckle averaging with the PW EH/SIS employs a stepper motor driven etalon to rotate the illumination beam, and thus the laser speckle pattern on the object, by $90^{\circ}$ between image series. That is, a series of images is acquired at each beam rotation and averaged to produce the image at each deformation state. The total number of frames which are averaged to produce each image is thus four times the number of frames to be averaged. Speckle averaging produces sharper fringes and reduces noise.

The PW EH/SIS allows the user to place labels and pointers on the image as graphics. A video caliper is also provided which may be calibrated to real world coordinates and allows for the on-screen measurement of detection sizes.

The LTI SC4000 was less useful in the evaluation of the test plates, due to its high shear angle, than was the variable shear angle PW EH/SIS. The former system was intended for use in the detection of large structural delaminations and damage. Also, the image enhancing capabilities of the PW EH/SIS facilitated the detection of small debonds in coatings. The LTI shearogram in Figure 5 may be compared to the PW shearograms in

\footnotetext{
${ }^{3}$ LTI Patent No. 5,094,528.
} 
Appendix Al.1 for the same plate, all of which utilized thermal excitation. Thus, the PW EH/SIS was utilized for this probability of detection study.

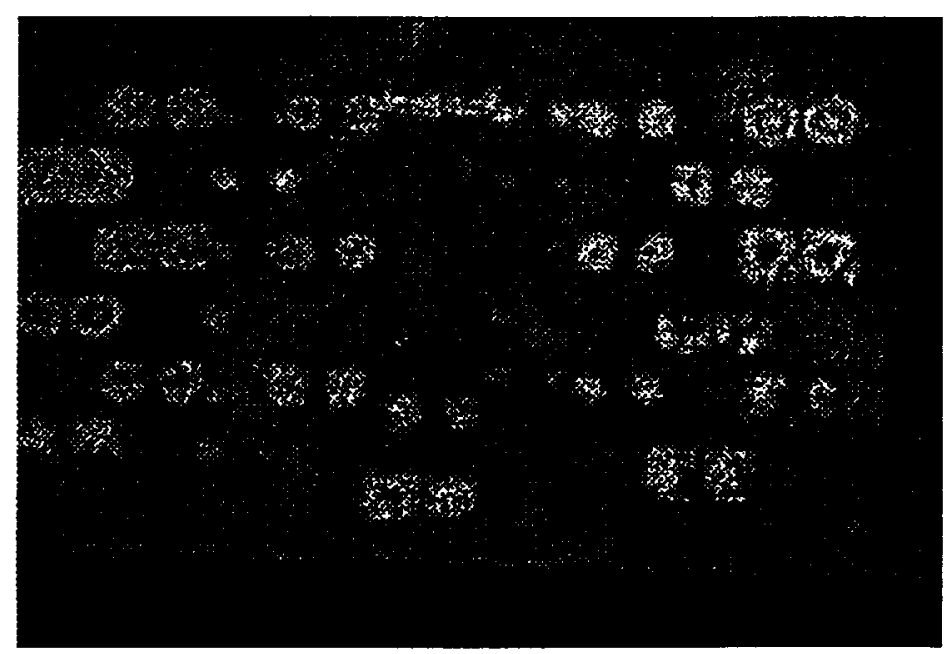

Figure 5. LTI SC4000 Shearogram of Panel 25.

The PW EH/SIS acquires the electronic shearograms as digital images via an NEC TI-23A charge coupled device (CCD) camera with a $480 \times 512$ pixel resolution. This camera is equipped with a $12.5-75 \mathrm{~mm}$ telephoto lens. The shearograms are displayed on a Sony PVM-1342Q video monitor and hard copies are produced by a Sony VP3000 video printer. Object illumination is supplied by an Adlas DPY325C light emitting diode (LED) pumped frequency doubled neodymium doped yttrium-aluminum garnet (Nd:YAG) laser with a power rating of 140 milliwatts $(\mathrm{mW})$ at a wavelength of 532 nanometers $(\eta \mathrm{m})$.

\subsubsection{Procedure:}

The painted plates were thermally excited to induce debond motion. The plates were lightly heated from the front with a hand-held heat gun. The undeformed images were captured while the plate was still hot, and the deformed images were acquired after it had cooled. That is, the measured deformation was thermal contraction associated with the cooling of the material system.

The PW EH/SIS lens was oriented 8 feet from the surface of the test panels. The zoom lens was used to adequately fill the field of view with the test panel image while allowing the best focus. Each test panel was inspected individually. Frame averaging was used with the number of frames set to four. Speckle averaging was also used, and optional traveling fringes were not displayed. The image shearing distance was adjusted to $2 \mathrm{~mm}$ horizontal.

Data was acquired in the form of electronic shearogram video images. The video caliper was used to measure the size of each detection in the vertical direction. Each of three inspectors acquired two shearograms of each plate. This resulted in 672 debond size measurements. That is, there were 84 observations of each of the eight standard debond sizes. The shearograms and measurements are included in Appendices A1.0 \& A2.0. 


\subsection{Analysis:}

The measured sizes of the detected debonds were analyzed numerically by the Probability of Detection Software System (POD/SS) ${ }^{4}$ AHAT routine. This software fits a POD curve of the form $\ln (\hat{\alpha})=\beta_{1}+\beta_{2} \ln (\alpha)$ where $\hat{\alpha}$ values are the measured debond sizes and $\alpha$ are the standard debond sizes.

\subsection{Results:}

The results of the POD/SS analysis are shown in Figures $6 \& 7$. It was found that the probability of detection is greater than $90 \%$ if the debond size is greater than $9.95 \mathrm{~mm}$. However, in order to achieve $95 \%$ confidence, the debond size must be greater than 15.62 $\mathrm{mm}$.

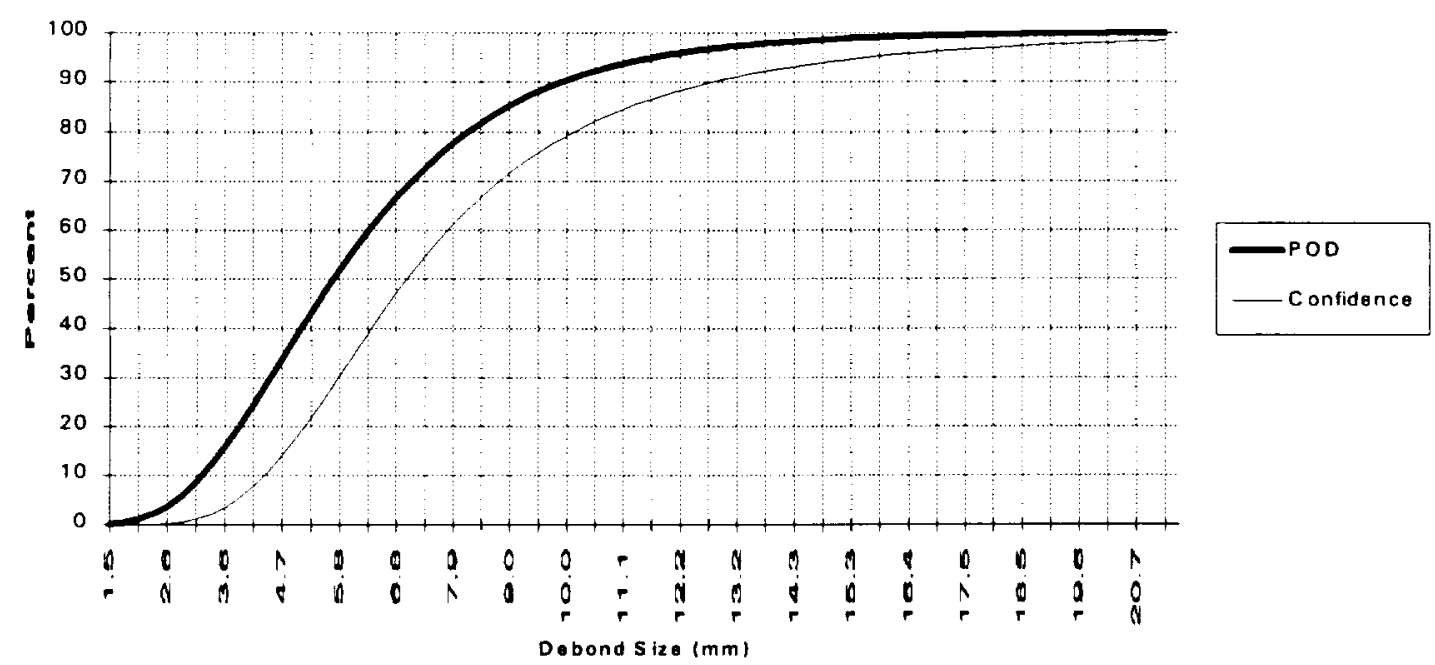

Figure 6. Electronic Shearography Probability of Detection of Debonds in Coatings (90/95: $15.62 \mathrm{~mm})$

${ }^{4}$ Berens, A.P., Hovey, P.W., Donahue, R.M., \& Craport, W.N., University of Dayton Research Institute, 1988. 


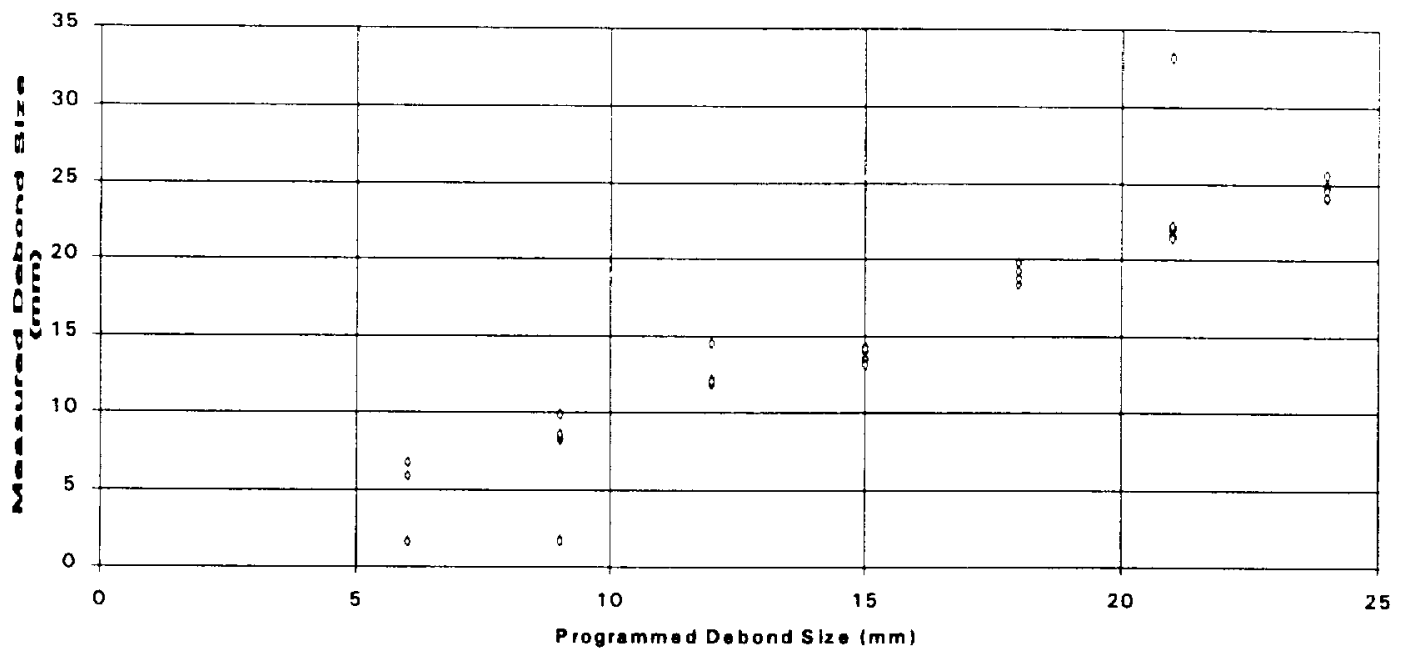

Figure 7. Electronic Shearography Coating Debond Size Measurement Scatter

The field of view in this experiment was approximately $305 \mathrm{~mm}$ ( $12 \mathrm{in}$.) wide. Thus, the minimum $90 / 95$ detection size is about $5.1 \%$ of the field of view. These results may be compared with a POD study conducted by Laser Technology, Inc. for an aluminum honeycomb aerospace battery housing. ${ }^{5}$ It was determined that the minimum flaw size for $90 / 95$ detection was $7.16 \mathrm{~mm}(0.282 \mathrm{in}$.) with a field of view $127 \mathrm{~mm}(5 \mathrm{in}$.) wide. Thus, the minimum size is about $5.6 \%$ of the field of view. These results compliment each other despite the different apparatus, material systems, and geometries involved.

\subsection{Discussion:}

The minimum debond size for $90 \%$ POD with $95 \%$ confidence is dependent upon several parameters. For example, while the minimum size in this study was found to be about $5 \%$ of the field of view, this proportion is dependent on the size of the field of view. That is, if the same setup and analysis, including a $2 \mathrm{~mm}$ shear distance, was used with a $4 \times 6$ feet field of view then the minimum size cannot be extrapolated to be $5 \% \times 6$ feet $=3.6$ inches. The minimum debond size is also dependent on the image shearing distance, which is in turn dependent on the object distance and image shearing angle. Even if the shearing angle is kept the same, allowing the shearing distance to change, then this type of extrapolation does not hold. If any procedure other than that described above is to be used, then a POD study must be conducted for that procedure.

The procedure used in this study was confined to the analysis of debonds on the $8 \times 12$ inch plates provided by NASA. If it is desired to conduct electronic shearography inspection for coating debonds over a large surface, say the entire surface of a RSRM, then, in the interest of time and expense, it may be preferable to evaluate a larger area with each inspection. For the reasons explained above, and because debonds on a large curved structure will exhibit different detections than those on a flat plate, a POD analysis should

\footnotetext{
${ }^{5}$ This POD study is summarized in Reference 6.
} 
be conducted on specimens which more closely resemble the area and curvature of the RSRM. However, the deviations associated with size and curvature may be simultaneously overcome by the development of an automated robotic or computer numerically controlled (CNC) electronic shearography system. Even if larger areas are to be inspected, the simplest form of such an automated system would significantly decrease the time, and perhaps long-term expense, required to inspect such a large structure. by the equation ${ }^{6}$

Electronic shearography fringe orders may be related to changes in surface slopes

$$
\partial w / \partial \mathbf{x}=-\lambda / 2 \delta \mathbf{x}
$$

For this study, a shearing distance of 2 millimeters (mm) was used. The PW EH/SIS laser provides illumination with a wavelength of 532 nanometers $(\eta \mathrm{m})$. From the equation above, each fringe in the resulting shearograms represents a change in surface slope of $0.133 \mathrm{~mm} / \mathrm{m}$. This may be expressed as 0.000133 radians or $0.00762^{\circ}$.

\subsection{Conclusions:}

Debonds of sizes 3-24 mm were simulated with aluminum foil inserts on $8 \times 12$ inch plates of the RSRM coating/substrate material system. A total of 84 observations of each of the 8 debond sizes were obtained with electronic shearography. The size of these detections were numerically analyzed. It was determined that, with the experimental parameters and procedures used, electronic shearography provides $90 \%$ probability of detection at $95 \%$ confidence for all debond sizes greater than $16.52 \mathrm{~mm}$, or about $5 \%$ of the field of view width.

\footnotetext{
${ }^{6}$ This relationship is derived in Reference 5.
} 
APPENDICES 


\section{A1.0 PW EH/SIS Shearograms:}

\section{A1.1 Panel 25:}

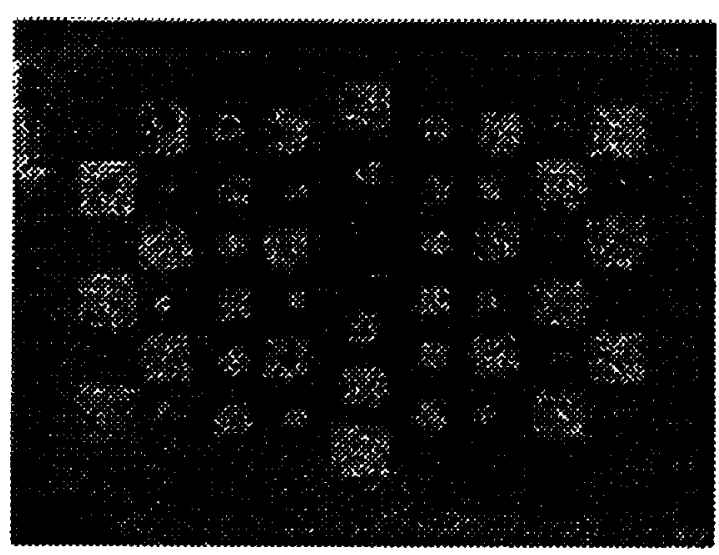

inspection B25-1

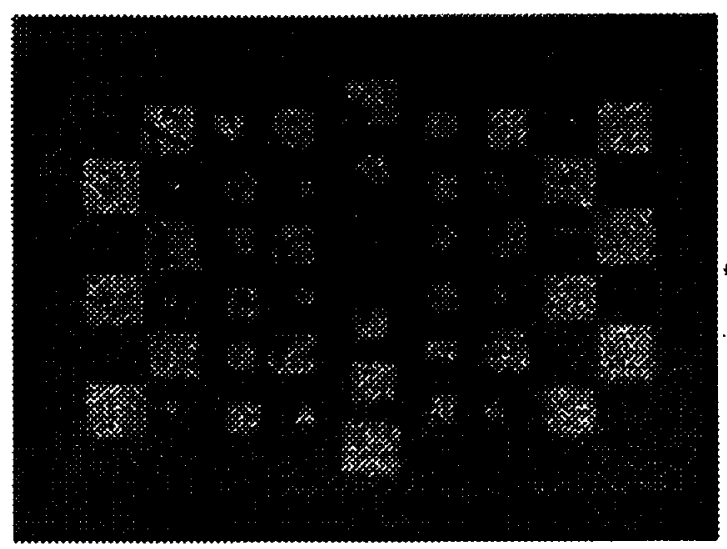

inspection M25-1

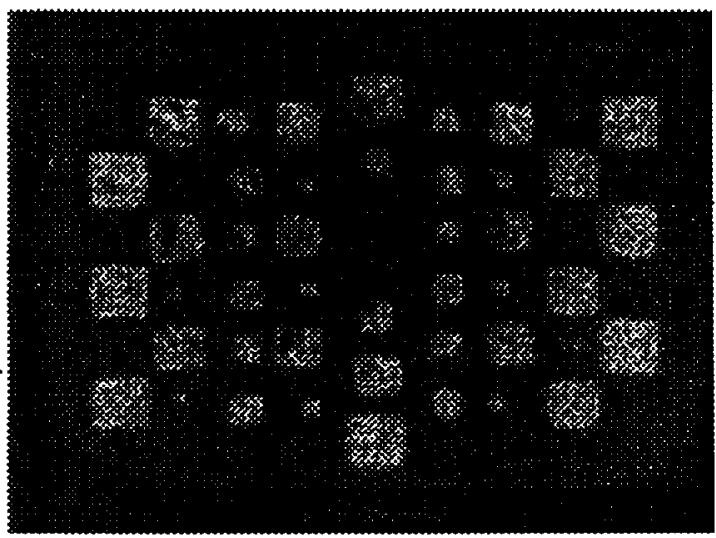

inspection P25-1

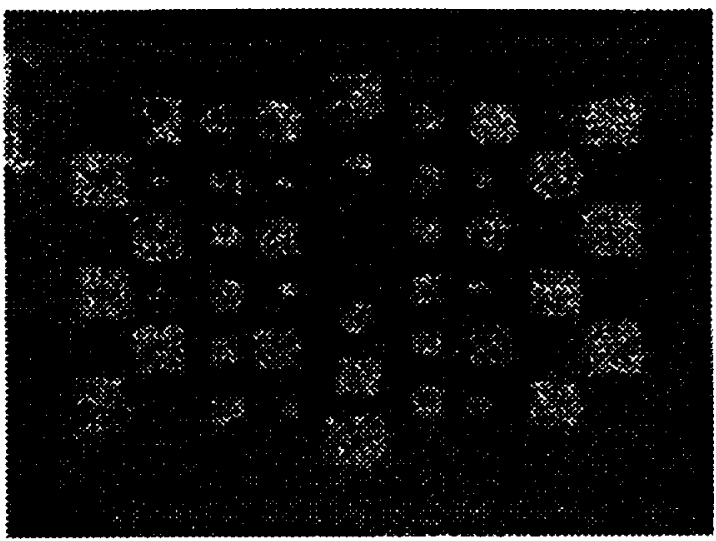

inspection B25-2

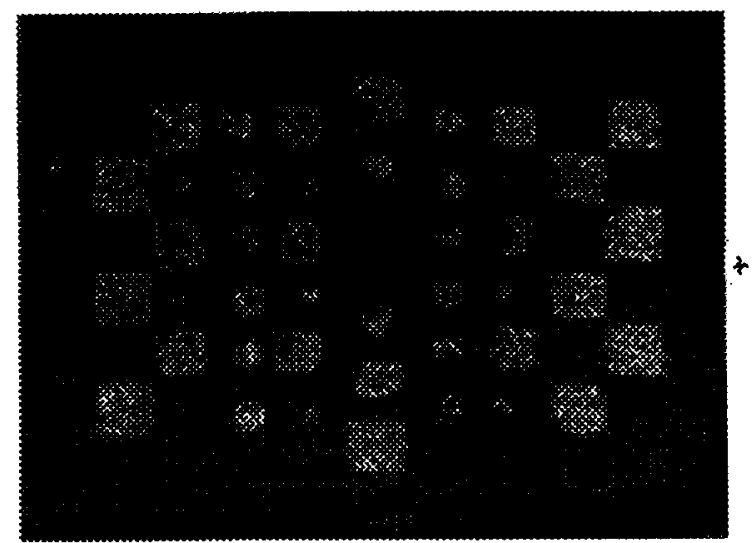

inspection M25-2

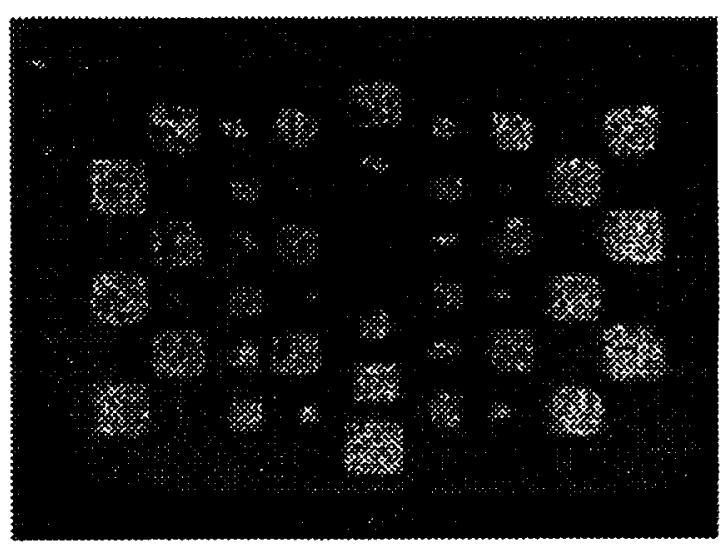

inspection $\mathrm{P} 25-2$ 


\section{A1.2 Panel 26:}

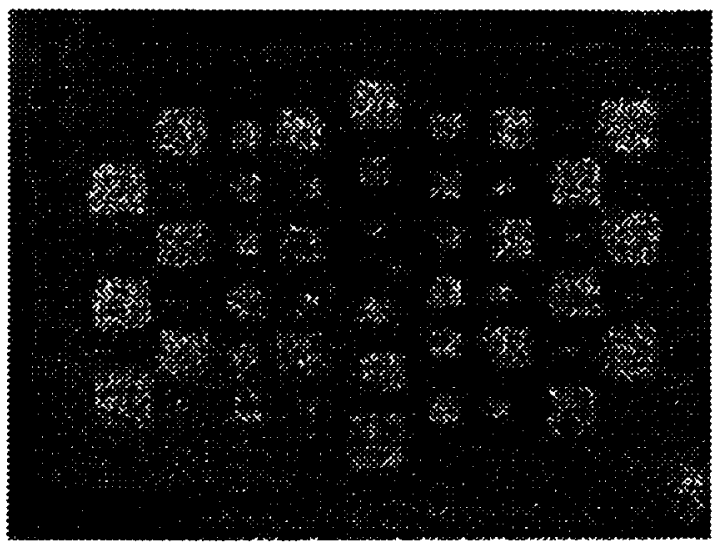

inspection B26-1

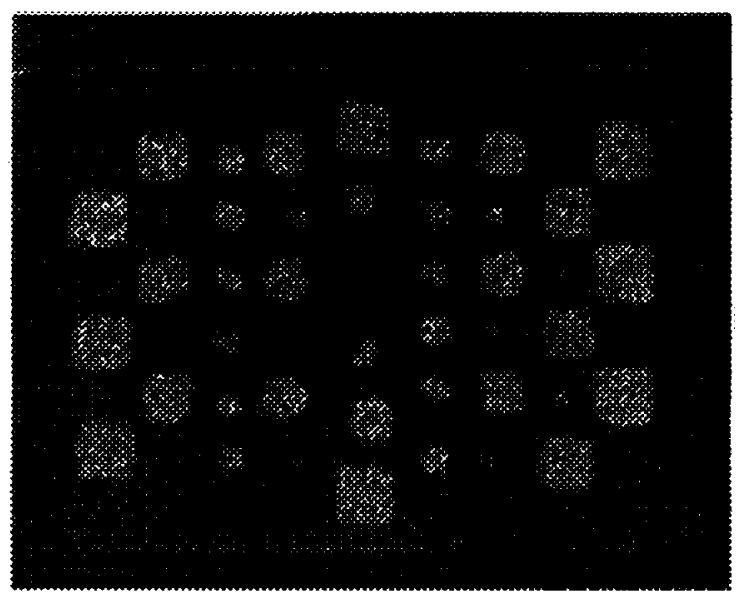

inspection M26-1

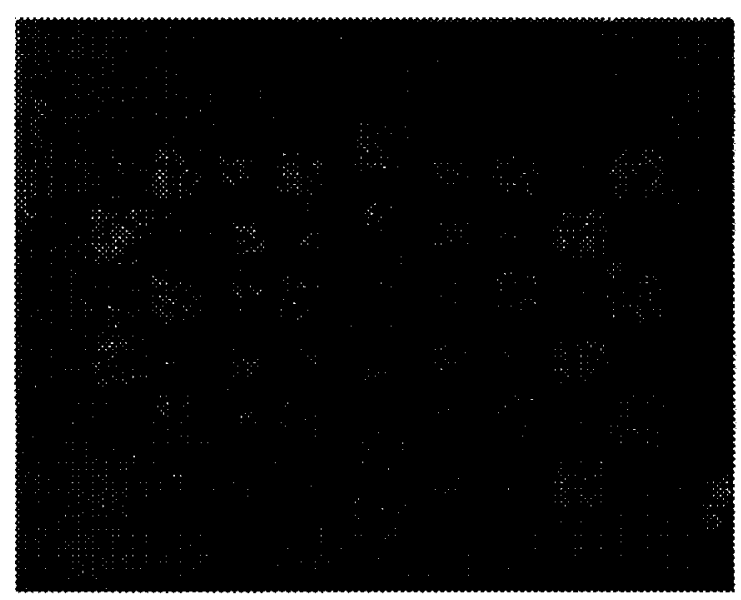

inspection P26-1

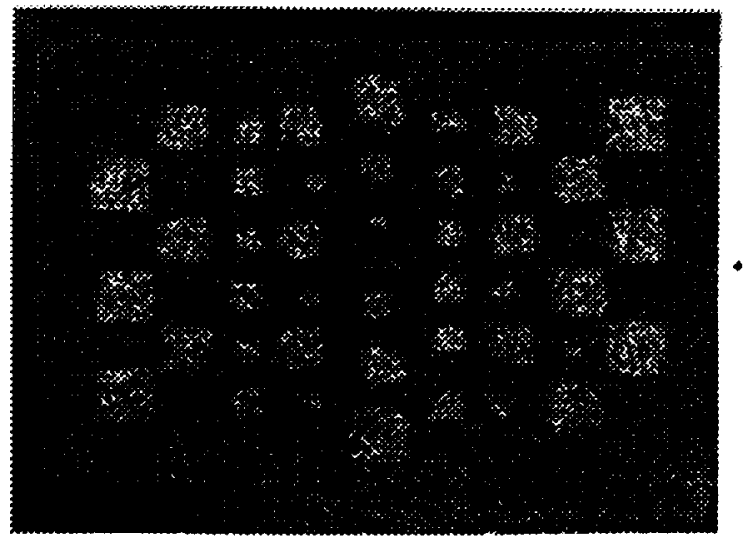

inspection B26-2

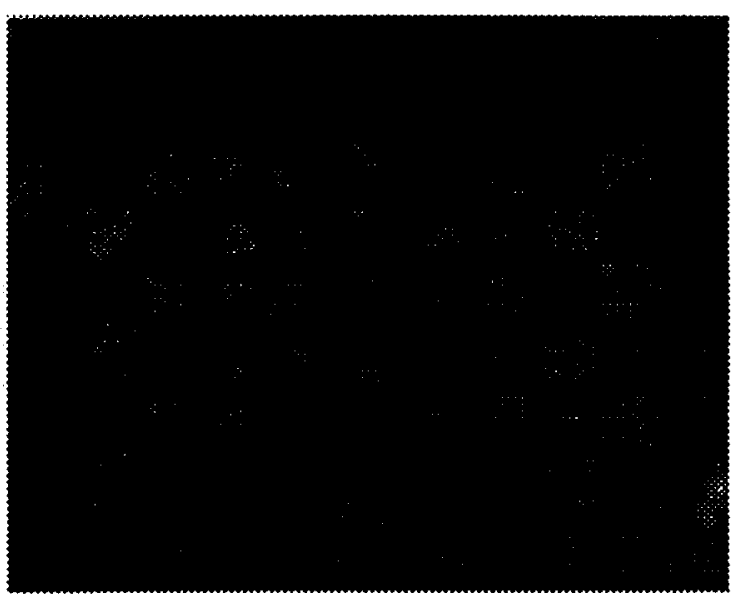

inspection M26-2

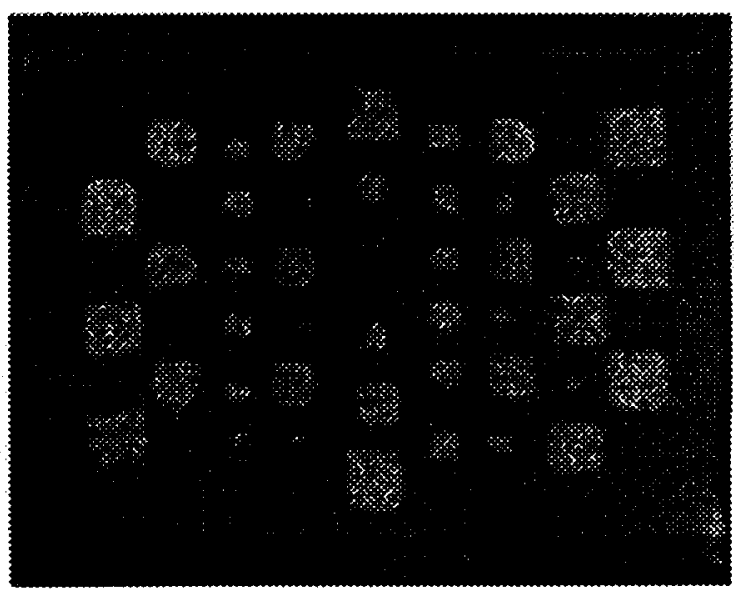

inspection P26-2 


\section{A2.0 PW EH/SIS Debond Size Measurements:}

\section{A2.1 Panel 25:}

\begin{tabular}{|c|c|c|c|c|c|c|c|}
\hline NAME & SIZE & B25-1 & B25-2 & M25-1 & M25-2 & P25-1 & P25-2 \\
\hline A1 & 24 & 23.09 & 24.10 & 23.09 & 23.10 & 23.26 & 21.84 \\
\hline A2 & 6 & 0.00 & 0.00 & 2.57 & 0.00 & 3.80 & 0.00 \\
\hline A3 & 18 & 19.51 & 18.97 & 17.44 & 17.40 & 18.52 & 17.09 \\
\hline A4 & 12 & 13.84 & 12.83 & 11.29 & 12.30 & 12.34 & 9.02 \\
\hline A5 & 18 & 18.97 & 18.97 & 17.96 & 18.50 & 18.99 & 17.57 \\
\hline $\mathrm{A5}$ & 12 & 14.88 & 15.90 & 11.80 & 13.80 & 10.92 & 10.45 \\
\hline A7 & 21 & 22.07 & 21.03 & 21.55 & 22.10 & 21.84 & 21.84 \\
\hline$A 8$ & 3 & 0.00 & 0.00 & 0.00 & 0.00 & 0.00 & 0.00 \\
\hline 81 & 3 & 0.00 & 0.00 & 0.00 & 0.00 & 0.00 & 0.00 \\
\hline $\mathrm{B} 2$ & 21 & 20.52 & 22.07 & 22.06 & 22.60 & 22.31 & 21.84 \\
\hline B3 & 9 & 14.38 & 12.83 & 8.21 & 11.30 & 10.92 & 7.60 \\
\hline B4 & 15 & 15.39 & 14.88 & 13.34 & 14.90 & 14.72 & 14.24 \\
\hline B5 & 9 & 8.71 & 7.70 & 7.70 & 9.25 & 7.60 & 6.17 \\
\hline$B 6$ & 15 & 13.34 & 13.84 & 13.85 & 13.80 & 14.24 & 13.23 \\
\hline B7 & 6 & 0.00 & 5.64 & 4.10 & 7.19 & 5.70 & 0.00 \\
\hline B8 & 24 & 25.65 & 24.10 & 24.63 & 24.60 & 24.21 & 24.21 \\
\hline C1 & 224 & 25.15 & 26.16 & 23.60 & 25.10 & 24.21 & 23.74 \\
\hline $\mathrm{C2}$ & 6 & 0.00 & 0.00 & 4.10 & 0.00 & 0.00 & 0.00 \\
\hline C3 & 18 & 21.03 & 20.02 & 16.93 & 19.50 & 18.99 & 18.99 \\
\hline $\mathrm{C4}$ & 12 & 12.32 & 14.88 & 11.80 & 10.80 & 11.39 & 8.55 \\
\hline C5 & 18 & 18.47 & 20.02 & 17.96 & 18.00 & 18.52 & 18.52 \\
\hline C6 & 12 & 14.38 & 11.81 & 12.31 & 12.90 & 11.39 & 10.45 \\
\hline $\mathrm{C7}$ & 21 & 22.07 & 21.54 & 21.04 & 20.50 & 21.36 & 22.31 \\
\hline C8 & 3 & 0.00 & 0.00 & 0.00 & 0.00 & 0.00 & 0.00 \\
\hline D1 & 3 & 0.00 & 0.00 & 0.00 & 0.00 & 0.00 & 0.00 \\
\hline D2 & 21 & 23.09 & 21.54 & 21.04 & 21.50 & 21.36 & 21.36 \\
\hline D3 & 9 & 12.32 & 8.71 & 9.24 & 8.71 & 8.55 & 6.17 \\
\hline D4 & 15 & 14.88 & 13.84 & 13.85 & 13.30 & 14.24 & 13.77 \\
\hline D5 & 9 & 9.75 & 8.71 & 8.72 & 9.25 & 7.60 & 5.70 \\
\hline D6 & 15 & 14.38 & 14.88 & 13.85 & 12.80 & 14.72 & 14.72 \\
\hline D7 & 6 & 8.71 & 5.13 & 4.10 & 6.68 & 6.17 & 6.65 \\
\hline D8 & 24 & 24.10 & 24.10 & 23.09 & 23.10 & 23.74 & 23.26 \\
\hline E1 & 24 & 25.65 & 24.10 & 23.60 & 25.10 & 23.26 & 24.21 \\
\hline$E 2$ & 6 & 7.70 & 0.00 & 0.00 & 0.00 & 6.17 & 0.00 \\
\hline E3 & 18 & 18.97 & 21.54 & 18.47 & 20.50 & 19.94 & 19.47 \\
\hline E4 & 12 & 13.84 & 12.83 & 9.24 & 11.30 & 11.87 & 10.45 \\
\hline E5 & 18 & 21.54 & 20.52 & 18.98 & 18.50 & 18.99 & 18.99 \\
\hline E6 & 12 & 16.41 & 12.32 & 12.83 & 14.40 & 14.24 & 12.82 \\
\hline E7 & 21 & 21.03 & 20.52 & 20.52 & 20.00 & 20.42 & 20.89 \\
\hline E8 & 3 & 0.00 & 0.00 & 0.00 & 0.00 & 0.00 & 0.00 \\
\hline
\end{tabular}




\begin{tabular}{|c|c|c|c|c|c|c|c|}
\hline F1 & 3 & 0.00 & 0.00 & 0.00 & 0.00 & 0.00 & 0.00 \\
\hline F2 & 21 & 23.09 & 22.58 & 21.04 & 22.80 & 22.34 & 21.36 \\
\hline F3 & 9 & 13.84 & 10.77 & 9.75 & 10.30 & 9.02 & 9.50 \\
\hline F4 & 15 & 15.39 & 14.88 & 13.34 & 12.30 & 13.29 & 15.67 \\
\hline F5 & 9 & 8.71 & 8.71 & 7.70 & 8.71 & 8.55 & 9.02 \\
\hline F6 & 15 & 15.39 & 14.38 & 12.31 & 13.80 & 13.77 & 14.72 \\
\hline F7 & 6 & 9.75 & 0.00 & 4.62 & 0.00 & 4.75 & 0.00 \\
\hline F8 & 24 & 24.10 & 24.64 & 22.58 & 25.10 & 22.79 & 23.74 \\
\hline G1 & 21 & 23.09 & 22.58 & 19.50 & 21.00 & 21.37 & 20.89 \\
\hline G2 & 15 & 13.34 & 13.34 & 13.34 & 13.30 & 11.87 & 9.50 \\
\hline G3 & 9 & 0.00 & 0.00 & 0.00 & 0.00 & 0.00 & 0.00 \\
\hline G4 & 3 & 0.00 & 0.00 & 0.00 & 0.00 & 0.00 & 0.00 \\
\hline G5 & 6 & 4.62 & 0.00 & 0.00 & 0.00 & 0.00 & 0.00 \\
\hline G6 & 12 & 14.88 & 15.39 & 14.88 & 16.40 & 14.72 & 15.19 \\
\hline G7 & 18 & 20.52 & 18.47 & 18.98 & 18.50 & 18.52 & 18.52 \\
\hline G8 & 24 & 26.70 & 24.64 & 24.11 & 24.60 & 24.21 & 24.21 \\
\hline
\end{tabular}

\section{A2.2 Panel 26:}

\begin{tabular}{|c|c|c|c|c|c|c|c|}
\hline NAME & SIZE & B26-1 & B26-2 & M26-1 & M26-2 & P26-1 & P26-2 \\
\hline A1 & 24 & 24.64 & 25.67 & 25.31 & 23.71 & 25.65 & 26.16 \\
\hline A2 & 6 & 0.00 & 0.00 & 4.40 & 2.82 & 0.00 & 0.00 \\
\hline A3 & 18 & 21.05 & 18.99 & 19.26 & 18.63 & 20.52 & 20.02 \\
\hline A4 & 12 & 11.81 & 13.35 & 11.55 & 11.85 & 11.81 & 13.34 \\
\hline A5 & 18 & 18.99 & 21.05 & 18.71 & 17.50 & 15.90 & 18.47 \\
\hline A5 & 12 & 13.86 & 14.89 & 12.65 & 11.85 & 7.70 & 10.26 \\
\hline A7 & 21 & 21.05 & 21.56 & 20.91 & 22.58 & 22.07 & 20.52 \\
\hline A8 & 3 & 0.00 & 0.00 & 0.00 & 0.00 & 0.00 & 0.00 \\
\hline B1 & 3 & 0.00 & 0.00 & 0.00 & 0.00 & 0.00 & 0.00 \\
\hline B2 & 21 & 21.05 & 22.59 & 21.46 & 22.01 & 22.07 & 22.58 \\
\hline B3 & 9 & 11.29 & 8.73 & 8.25 & 9.03 & 9.75 & 9.25 \\
\hline B4 & 15 & 14.89 & 16.43 & 11.00 & 14.11 & 14.88 & 13.84 \\
\hline B5 & 9 & 11.81 & 9.24 & 8.80 & 9.03 & 7.19 & 7.19 \\
\hline B6 & 15 & 13.86 & 14.37 & 12.65 & 14.68 & 12.83 & 12.32 \\
\hline B7 & 6 & 6.67 & 0.00 & 0.00 & 0.00 & 0.00 & 0.00 \\
\hline B8 & 24 & 25.67 & 26.18 & 25.31 & 24.84 & 25.15 & 25.15 \\
\hline C1 & 224 & 25.67 & 24.64 & 26.96 & 25.40 & 26.16 & 26.16 \\
\hline C2 & 6 & 7.19 & 0.00 & 4.40 & 4.52 & 7.19 & 5.13 \\
\hline C3 & 18 & 21.56 & 18.48 & 19.81 & 19.19 & 20.52 & 20.01 \\
\hline C4 & 12 & 13.35 & 13.35 & 13.20 & 11.85 & 11.81 & 11.81 \\
\hline C5 & 18 & 17.97 & 18.48 & 18.71 & 20.32 & 18.97 & 18.47 \\
\hline C6 & 12 & 12.83 & 10.27 & 9.35 & 11.85 & 11.81 & 9.75 \\
\hline C7 & 21 & 20.53 & 20.53 & 21.46 & 21.45 & 22.07 & 21.03 \\
\hline C8 & 3 & 0.00 & 0.00 & 0.00 & 3.95 & 0.00 & 0.00 \\
\hline D1 & 3 & 0.00 & 0.00 & 1.65 & 0.00 & 0.00 & 0.00 \\
\hline
\end{tabular}




\begin{tabular}{|c|c|c|c|c|c|c|c|}
\hline D2 & 21 & 22.59 & 22.59 & 22.01 & 21.45 & 22.58 & 23.60 \\
\hline D3 & 9 & 11.29 & 9.75 & 7.15 & 6.21 & 7.19 & 8.71 \\
\hline D4 & 15 & 14.89 & 13.86 & 13.20 & 12.98 & 14.88 & 14.88 \\
\hline D5 & 9 & 10.78 & 8.73 & 0.00 & 7.90 & 7.19 & 0.00 \\
\hline D6 & 15 & 16.43 & 13.86 & 13.20 & 11.68 & 12.83 & 10.77 \\
\hline D7 & 6 & 0.00 & 0.00 & 0.00 & 5.08 & 0.00 & 0.00 \\
\hline D8 & 24 & 24.64 & 26.18 & 25.31 & 24.27 & 24.64 & 23.60 \\
\hline E1 & 24 & 24.64 & 25.67 & 25.31 & 24.84 & 25.15 & 25.65 \\
\hline E2 & 6 & 7.19 & 6.16 & 6.05 & 6.21 & 8.20 & 7.19 \\
\hline E3 & 18 & 19.51 & 19.51 & 19.81 & 20.32 & 20.01 & 20.01 \\
\hline E4 & 12 & 11.81 & 12.83 & 13.20 & 12.42 & 11.28 & 12.32 \\
\hline E5 & 18 & 19.51 & 21.05 & 20.91 & 19.19 & 20.01 & 20.02 \\
\hline E6 & 12 & 11.81 & 10.78 & 11.00 & 12.42 & 9.25 & 8.71 \\
\hline E7 & 21 & 21.56 & 23.10 & 23.11 & 22.01 & 22.07 & 21.54 \\
\hline E8 & 3 & 0.00 & 0.00 & 0.00 & 0.00 & 0.00 & 0.00 \\
\hline F1 & 3 & 0.00 & 0.00 & 0.00 & 0.00 & 0.00 & 0.00 \\
\hline F2 & 21 & 22.08 & 23.10 & 24.21 & 22.01 & 23.60 & 23.60 \\
\hline F3 & 9 & 12.32 & 10.78 & 8.25 & 9.50 & 7.19 & 9.25 \\
\hline F4 & 15 & 16.94 & 14.37 & 12.65 & 13.55 & 14.38 & 14.38 \\
\hline F5 & 9 & 9.75 & 9.24 & 9.90 & 7.34 & 8.20 & 7.70 \\
\hline F6 & 15 & 14.89 & 14.37 & 12.10 & 14.11 & 14.38 & 8.71 \\
\hline F7 & 6 & 0.00 & 0.00 & 0.00 & 4.52 & 0.00 & 0.00 \\
\hline F8 & 24 & 25.67 & 25.67 & 26.41 & 24.27 & 25.15 & 25.65 \\
\hline G1 & 21 & 23.10 & 23.62 & 23.11 & 22.01 & 24.10 & 22.58 \\
\hline G2 & 15 & 15.40 & 14.37 & 14.86 & 12.98 & 12.32 & 13.84 \\
\hline G3 & 9 & 11.29 & 6.67 & 0.00 & 3.95 & 5.13 & 5.64 \\
\hline G4 & 3 & 0.00 & 0.00 & 0.00 & 2.82 & 0.00 & 0.00 \\
\hline G5 & 6 & 5.65 & 0.00 & 0.00 & 2.26 & 4.62 & 0.00 \\
\hline G6 & 12 & 14.37 & 14.89 & 12.10 & 14.68 & 13.84 & 13.32 \\
\hline G7 & 18 & 20.53 & 20.53 & 21.46 & 19.19 & 19.51 & 20.52 \\
\hline G8 & 24 & 27.21 & 26.70 & 27.51 & 24.84 & 26.70 & 26.16 \\
\hline & & & & & & & \\
\hline
\end{tabular}




\section{A3.0 References:}

1. Boone, P.M. "Determination of Slope and Strain Contours by Double-exposure Shearing Interferometry", Experimental Mechanics, August 1975

2. Engel, J.E., and Burleigh, D.D., "Validation of Laser Shearography Testing for Fixed Foam Insulation Bonds", Review of Progress in Quantitative Nondestructive Evaluation, Vol. 9, 1990.

3. Hung, Y.Y., "Shearography: A New Optical Method for Strain Measurement and Nondestructive Testing", Optical Engineering, May/June 1982.

4. Hung, Y.Y., "Shearography: A New Strain-Measurement Technique and a Practical Approach to Nondestructive Testing", SEM Manual on Experimental Methods for Mechanical Testing of Composites, 1989.

5. Lansing, M.D., Workman, G.A., Theory and Application of Electronic Shearography, Final Technical Report for NASA DO99, Due August 1994.

6. Laser Technology, Inc., Advanced Shearography NDT, 25 May 1994.

7. Mohanty, R.K., Joenathan, C., and Sirohi, R.S., "Speckle and Speckle-Shearing Interferometers Combined for the Simultaneous Determination of Out-of-plane Displacement and Slope", Applied Optics, 15 September 1985.

8. Mohanty, R.K., Joenathan, C., and Sirohi, R.S., "High Sensitivity Tilt Measurement by Speckle Shear Interferometry", Applied Optics, 15 May 1986.

9. Newman, John W., "Inspection of Aircraft Structure With Advanced Shearography", 1990 ASNT Fall Conference, 10 October 1990.

10. Owner-Peterson, M., "Digital Speckle Pattern Shearing Interferometry: Limitations and Prospects", Applied Optics, 1 July, 1991.

11. Tay, C.J., Chau, F.S., Shang, H.M., Shim, V.P.W., and Toh, S.L., "The Measurement of Slope Using Shearography", Optics and Lasers in Engineering, 1990.

12. Toh, S.L, Shang, H.M., Chau, F.S., Tay, C.J., "Flaw Detection in Composites Using Time-Average Shearography", Optics and Laser Technology, Vol. 23, No. 1, 1991 . 


\begin{tabular}{|c|c|}
\hline 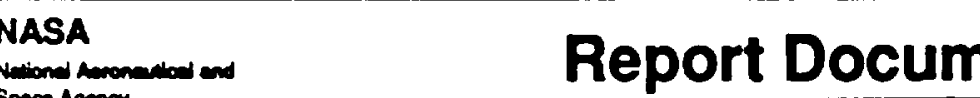 & t Page \\
\hline 1. Repon No. & P. Reaplent's Catalog No. \\
\hline \multirow{2}{*}{$\begin{array}{l}\text { 4. This and subtide } \\
\text { Prolbability of Detection of Dofocts in } \\
\text { Coatings with Electronic Shearography }\end{array}$} & $\begin{array}{l}\text { P. Repon Dus } \\
\text { Juno 2, } 1994\end{array}$ \\
\hline & $\begin{array}{l}\text { 3. Performing Organization Code } \\
\text { Research Institute, UAH }\end{array}$ \\
\hline \multirow{2}{*}{$\begin{array}{l}\text { 7. Aurthor(a) } \\
\text { Gary A. Maddux, Charies M. Horton, Matthow D. Laneing, } \\
\text { Willam J. Gnacek, Patrick L Nowton }\end{array}$} & $\begin{array}{l}\text { 3. Pertorming Organization Repont No. } \\
\text { 5-33267 }\end{array}$ \\
\hline & $\begin{array}{l}\text { 10. Work Unit No. } \\
\text { Delivery Order } * 80\end{array}$ \\
\hline \multirow{2}{*}{$\begin{array}{l}\text { UAH Research Institute } \\
\text { University of Alabama in Huntsville } \\
\text { Huntsville, AL } 35899\end{array}$} & $\begin{array}{l}\text { 11. Contrect or Grant No. } \\
\text { NAS8-38609 }\end{array}$ \\
\hline & 13. Typo of repont and Pertod covered \\
\hline \multirow{2}{*}{$\begin{array}{l}\text { 12. Sponeoring Aoency Name and Addreas } \\
\text { National Aeronautics and Space Administration } \\
\text { George C. Marshall Space Flight Center } \\
\text { Huntsville, Alabama } 35812\end{array}$} & $\begin{array}{l}\text { Final Technical } \\
03 \text { June } 1993 \text { through } 02 \text { June } 1994\end{array}$ \\
\hline & 14. Sponeoring Apency Code \\
\hline
\end{tabular}

16. Supplomentay Notoe

16Abedred

The goal of this research was to utilize statistical mothods to evaluate the probability of detection (POD) of defects in coatings using electronic shearography. The coating system utilized in the POD studies was to be the paint system currently utilized on the external casings of the NASA Space Transportation System (STS) Revised Solid Rocket Motor (RSRM) boosters. The population of samples was to be large enough to determine the minimum defect size for $90 \%$ probability of detection of $95 \%$ confidence POD on these coatings. Also, the best methods to excite coatings on aerospace components to induce deformations for measurement by electronic shearography were to be determined.

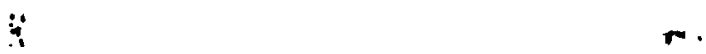

17. Koy Words (Sugpoesed by Aurthora(s))

Shearography

Probability of Dotection

18. Dictibution Statement

TBA

19. Securty Clates (of this report)

20. Scourity Cheas. (of this paop)
Unclaselfied
21. No. at pages
15

Unclassified

Unclasinind 